\title{
Estimasi Komponen Variansi pada Rancangan Faktorial Acak Lengkap Menggunakan Metode Generalized Least Squares
}

\author{
A. Muthiah Nur Angriany*1, Georgina Maria Tinungki², Raupong ${ }^{3 *}$
}

\begin{abstract}
s
Experiment design is a test or a row of test by using both statistical description and inference statistical. The aim of this test is to change an input to become an output as a respond of the experiment. In the experiment design, variance of factor $\mathrm{A}, \mathrm{B}, \mathrm{AB}$ error of variance are called as variant component. The aim of this study is to estimate variance component on complete random factorial design for fixed model and mixed model by using Generalized Least Squares (GLS)method, where GLS method as a development of Ordinary Least Square method. It used to be applied on data of complete random factorial design, namely like the influence to density pelleting food which is caused by increasing adhesive material and longtime in storage. The results show that there is no influence of increasing adhesive material to the density of pelleting food. In addition, there exist of diversity of longtime of storage and there exists a diversity interaction between adding adhesive material and long of time of storage to the density of pelleting food
\end{abstract}

Keywords: Generalized Least Squares, variance component, complete random factorial design

\begin{abstract}
Abstrak
Perancangan percobaan adalah suatu uji atau sederet uji baik itu menggunakan statistika deskripsi maupun statistika inferensi, yang bertujuan untuk mengubah peubah input menjadi suatu output yang merupakan respon dari percobaan tersebut. Dalam perancangan percobaan, variansi dari faktor A, variansi dari faktor $\mathrm{B}$, variansi interaksi faktor $\mathrm{AB}$, dan variansi galat disebut dengan komponen varian. Penelitian ini bertujuan untuk mengestimasi komponen variansi pada rancangan faktorial acak lengkap model tetap dan model campuran menggunakan metode Generalized Least Squares (GLS), dimana metode GLS adalah pengembangan dari metode Ordinary Least Square yang biasa digunakan untuk mengatasi asumsi homogenitas yang biasa dilanggar dalam perancangan percobaan. Metode tersebut diterapkan pada data rancangan faktorial acak lengkap yaitu pengaruh berat jenis pakan pellet dengan kombinasi perlakuan penambahan bahan perekat dan lama penyimpanan. Hasil menunjukkan bahwa tidak terdapat pengaruh penambahan bahan perekat terhadap berat jenis pakan pellet. Selain itu, terdapat keragaman faktor lama penyimpan dan terdapat keragaman interaksi antara faktor penambahan perekat dan lama penyimpanan terhadap berat jenis pakan pellet.
\end{abstract}

Kata kunci: Generalized Least Squares, komponen variansi, rancangan faktorial acak lengkap

\section{PENDAHULUAN}

Perancangan percobaan adalah suatu uji atau sederet uji baik menggunakan statistika deskripsi maupun statistika inferensi, yang bertujuan untuk mengubah peubah input menjadi suatu output yang merupakan respon dari perlakuan tersebut [7]. Dalam beberapa perlakuan, terdapat faktor yang digunakan lebih dari satu sehingga biasanya terjadi interaksi antara faktor yang diterapkan, percobaan ini disebut dengan percobaan faktorial. Rancangan faktorial dengan rancangan acak lengkap

* Program studi Statisika, Universitas Hasanuddin

Email: ${ }^{1}$ amuthiah97@gmail.com, ${ }^{2}$ ina_matematika@yahoo.com,

${ }^{3}$ Raupong.stat.uh@gmail.com 


\section{A. Muthiah Nur Angriany, Georgina Maria Tinungki, Raupong}

merupakan percobaan faktorial dengan rancangan dasar RAL, faktor yang digunakan terdiri dari dua faktor, yaitu faktor A dengan a taraf dan faktor B dengan b taraf, serta kedua faktor yang saling berinteraksi. Dalam rancangan faktorial dua faktor, variansi faktor A, variansi faktor B, variansi interaksi antara faktor A dan faktor B, dan variansi galat disebut komponen variansi [3].

Beberapa metode yang dapat digunakan dalam mengestimasi komponen variansi, diantaranya analisis variansi (ANAVA), metode maksimum Likelihood (MLE) dan metode restricted maximum Likelihood (REML) [12] . Metode ANAVA merupakan suatu teknik penguraian variansi total ke dalam komponen-komponen model, dimana metode estimasi parameter yang digunakan yaitu ordinary least square (OLS) untuk perancangan yang semua asumsinya terpenuhi. Metode generalized least square (GLS) sebagai pengembangan metode OLS untuk mengatasi asumsi homogenitas yang sering dilanggar dalam asumsi perancangan percobaan statistika Beberapa peneliti yang mengkaji komponen variansi diantarnya adalah Hartley dan Rou [3], R.R Corbeil and S.R [2], Hasby, dkk [5].Penerapan Generalized Least Square sendiri dalam perancangan percobaan telah dibahas pada tahun 2013 [9] dalam skripsi berjudul "Analisis Faktorial RAL dengan Metode Generalized Least Square(GLS)" dengan hasil bahwa dalam menaksir parameter metode GLS lebih baik dari OLS.

\section{Tinjauan Pustaka}

\subsection{Percobaan Faktorial dengan Rancangan Acak Lengkap}

Percobaan faktorial dengan rancangan dasar RAL adalah percobaan faktorial yang menggunakan RAL sebagai rancangan dasar, sedangkan faktor yang dicobakan lebih dari satu. Dalam percobaan faktorial, akan berhadapan dengan kombinasi dari taraf-taraf faktor yang dicobakan disebut sebagai perlakuan.

Model linier untuk percobaan faktorial yang terdiri dari dua faktor dengan menggunakan rancangan dasar RAL adalah sebagai berikut :

$Y_{i j k}=\mu+\alpha_{i}+\beta_{j}+(\gamma)_{i j}+\varepsilon_{i j k} ; i=1,2, \ldots, a ; j=1,2, \ldots, b ; k=1,2, \ldots, r$

Keterangan : $Y_{i j k}=$ respon perlakuan pada faktor A taraf ke- $i$, faktor B taraf ke-j dan ulangan ke- $k$ ; $\mu$ =rataan umum ; $\alpha_{i}=$ Pengaruh utama faktor A taraf ke- $i ; \beta_{j}=$ pengaruh utama faktor B taraf ke-j; $(\gamma)_{i j}=$ pengaruh interaksi faktor A taraf ke- $i$ dan faktor B taraf ke-j; $\varepsilon_{i j k}=$ galat pada faktor A taraf ke$i$, faktor B taraf ke-j dan ulangan ke- $k$.

Beberapa model pada rancangan faktorial diantaranya adalah model tetap, model acak, dan model campuran. Jika faktor A dengan a taraf dan faktor B dengan b taraf tetap, maka disebut model tetap. Jika faktor A dengan a taraf dan faktor B dengan b taraf acak, maka disebut model acak. Sedangkan jika faktor A dengan a taraf tetap dan faktor B dengan b taraf acak atau sebaliknya disebut dengan model campuran. Asumsi apabila faktor A dengan a taraf dan faktor B dengan $\mathrm{b}$ taraf tetap adalah $\sum_{i} \alpha_{i}=\sum_{j} \beta_{j}=\sum_{i} \gamma_{i j}=\sum_{j} \gamma_{i j}=0$, sedangkan asumsi jika faktor A dengan a taraf tetap dan faktor $\mathrm{B}$ dengan $\mathrm{b}$ taraf acak adalah $\sum_{i} \alpha_{i}=0, \quad \beta_{j} \sim N\left(0, \sigma_{\beta}{ }^{2}\right), \quad(\gamma)_{i j} \sim N\left(0, \sigma_{\beta}{ }^{2}\right)$, dan $\varepsilon_{i j k} \sim N\left(0, \sigma^{2}\right)[3]$

\subsection{Uji Asumsi Rancangan}

1. Galat berdistribusi normal

Uji normalitas digunakan untuk melihat apakah data menyebar normal atau tidak. Kenormalan data dapat ditentukan dengan menggunakan probability plot normal, dengan melihat titik-titik dugaan galat jika mengikuti garis diagonal berarti galat berdistribusi normal. Asumsi normalitas juga dapat diuji dengan menggunakan uji Liliefors.

2. Variansi galat homogen

Asumsi homogenitas mensyaratkan bahwa distribusi galat untuk masing-masing kelompok harus memiliki variansi yang homogen. Uji formal yang dapat digunakan untuk memeriksa asumsi kehomogenan adalah uji Bartlett [8]. 


\section{A. Muthiah Nur Angriany, Georgina Maria Tinungki, Raupong}

3. Galat percobaan saling bebas

Kebebasan galat percobaan lebih umum diartikan sebagai tidak ada korelasi antar galat. galat dari salah satu pengamatan yang mempunyai nilai tertentu harus tidak bergantung dari nilai-nilai galat pengamatan yang lain [3]. Pengujian terhadap asumsi kebebasan antar galat percobaan dilakukan dengan cara membuat plot antara nilai sisaan dengan nilai dugaan pengamatan. Apabila grafik yang terbentuk berfluktuasi secara acak di sekitar nol, maka dapat dikatakan bahwa suku-suku galat percobaan saling bebas.

\subsection{Struktur Data Pengamatan dan Struktur Analisis Variansi}

Tabel 2.1 Tabulasi data yang terdiri dari faktor A dan a taraf, faktor B dengan b taraf, $\mathrm{r}$ ulangan

\begin{tabular}{|c|c|c|c|c|c|c|}
\hline \multirow{2}{*}{ Faktor A } & \multirow{2}{*}{ Ulangan } & \multicolumn{4}{|c|}{ Faktor B } & \multirow{2}{*}{ Total Baris $\left(y_{i . .}\right)$} \\
\hline & & 1 & 2 & $\ldots$ & $B$ & \\
\hline \multirow[t]{5}{*}{1} & 1 & $y_{111}$ & $y_{121}$ & $\begin{array}{l} \\
\cdots\end{array}$ & $y_{1 b 1}$ & $y_{1.1}$ \\
\hline & 2 & $y_{112}$ & $y_{122}$ & $\cdots$ & $y_{1 b 2}$ & $y_{1.2}$ \\
\hline & $\vdots$ & $\vdots$ & $\vdots$ & $\cdots$ & $\vdots$ & $\vdots$ \\
\hline & $r$ & $y_{11 r}$ & $y_{12 r}$ & $\cdots$ & $y_{1 b r}$ & $y_{1 . r}$ \\
\hline & $y_{1 j}$ & $y_{11}$ & $y_{12}$ & $\cdots$ & $y_{1 b}$ & $y_{1 . .}$ \\
\hline \multirow[t]{5}{*}{2} & 1 & $y_{211}$ & $y_{221}$ & $\cdots$ & $y_{2 b 1}$ & $y_{2.1}$ \\
\hline & 2 & $y_{212}$ & $y_{222}$ & $\cdots$ & $y_{2 b 2}$ & $y_{2.2}$ \\
\hline & $\vdots$ & $\vdots$ & $\vdots$ & $\cdots$ & $\vdots$ & $\vdots$ \\
\hline & $r$ & $y_{21 r}$ & $y_{22 r}$ & $\cdots$ & $y_{2 b r}$ & $y_{2 . r}$ \\
\hline & $y_{2 j}$ & $y_{21}$ & $y_{22}$ & $\cdots$ & $y_{2 b}$ & $y_{2 . .}$ \\
\hline$\vdots$ & $\vdots$ & $\vdots$ & $\vdots$ & $\cdots$ & $\vdots$ & $\vdots$ \\
\hline \multirow[t]{5}{*}{$A$} & 1 & $y_{a 11}$ & $y_{a 21}$ & $\cdots$ & $y_{a b 1}$ & $y_{a .1}$ \\
\hline & 2 & $y_{a 12}$ & $y_{a 22}$ & $\cdots$ & $y_{a b 2}$ & $y_{a .2}$ \\
\hline & $\bar{\vdots}$ & $\vdots$ & $\vdots$ & $\cdots$ & $\vdots$ & $\vdots$ \\
\hline & $r$ & $y_{a 1 r}$ & $y_{a 2 r}$ & $\cdots$ & $y_{a b r}$ & $y_{a . r}$ \\
\hline & $y_{i j}$ & $y_{a 1}$ & $y_{a 2}$ & $\cdots$ & $y_{a b .}$ & $y_{a . .}$ \\
\hline \multicolumn{2}{|c|}{ Total Kolom $\left(y_{. j .}\right)$} & $y_{.1 .}$ & $y_{.2 .}$ & $\cdots$ & $y_{. b .}$ & $y_{\ldots}$ \\
\hline
\end{tabular}

Berikut adalah struktur tabel analisis variansi (ANAVA) untuk rancangan faktorial acak lengkap [7]

Tabel 2.2 Struktur tabel ANAVA pada rancangan faktorial acak lengkap

\begin{tabular}{|c|c|c|c|c|}
\hline Sumber Variansi & $d b$ & $J K$ & $K T$ & $F_{\text {Hitung }}$ \\
\hline \multicolumn{5}{|c|}{ Model tetap (faktor A dan faktor B tetap) } \\
\hline $\mathrm{A}$ & $a-1$ & $J K A$ & $K T A$ & $\frac{K T A}{K T G}$ \\
\hline $\mathrm{B}$ & $b-1$ & $J K B$ & $K T B$ & $\frac{K T B}{K T G}$ \\
\hline $\mathrm{AB}$ & $(a-1)(b-1)$ & $J K A B$ & $K T A B$ & $\frac{K T A B}{K T G}$ \\
\hline
\end{tabular}


A. Muthiah Nur Angriany, Georgina Maria Tinungki, Raupong

\begin{tabular}{|c|c|c|c|c|}
\hline Galat & $a b(r-1)$ & $J K G$ & KTG & \\
\hline Total & $a b r-1$ & JKT & \\
\hline \multicolumn{5}{|c|}{ Model campuran (faktor A tetap dan faktor B acak) } \\
\hline A & $a-1$ & $J K A$ & KTA & $\frac{K T A}{K T A B}$ \\
\hline B & $b-1$ & $J K B$ & KTB & $\frac{K T B}{K T G}$ \\
\hline AB & $(a-1)(b-1)$ & $J K A B$ & KTAB & $\frac{K T A B}{K T G}$ \\
\hline Galat & $a b(r-1)$ & $J K G$ & KTG & \\
\hline Total & $a b r-1$ & JKT & & \\
\hline
\end{tabular}

Nilai taksiran untuk komponen variansi pada rancangan faktorial RAL model campuran dengan faktor A tetap dan faktor B acak yaitu sebagai berikut (Searle dkk, 2006):

$$
\begin{aligned}
\sigma_{e}^{2} & =K T G \\
\sigma_{\beta}^{2} & =\frac{1}{a r}[K T B-K T A B] \\
\sigma_{\gamma}^{2} & =\frac{1}{r}[K T A B-K T G]
\end{aligned}
$$

\subsection{Regresi dengan Metode Ordinary Least Square}

Bentuk umum regresi adalah

$$
(2.5)
$$

$$
Y_{i}=\beta_{0}+\beta_{1} X_{1 i}+\beta_{2} X_{2 i}+\cdots+\beta_{k} X_{k i}+\varepsilon_{i} \quad \text { atau } \quad \mathbf{Y}=\mathbf{X} \boldsymbol{\beta}+\boldsymbol{\varepsilon}
$$

OLS merupakan salah satu metode yang banyak digunakan oleh para ilmuwan atau peneliti dalam proses perhitungan suatu persamaan regresi. Cara kerja dengan meminimumkan jumlah kuadrat galat.

Agar taksiran OLS bersifat BLUE (Best Linier Unbiased Estimator) maka harus dipenuhi beberapa asumsi dasar yaitu : nilai harapan $\boldsymbol{\varepsilon}$ sama dengan nol atau $E(\boldsymbol{\varepsilon})=0, \boldsymbol{\varepsilon}$ memiliki variansi yang konstan atau tidak terjadi heteroskedastisitas, tidak ada korelasi antara $\varepsilon_{i}$ dan $\varepsilon_{j}$ dimana $i \neq j$ atau tidak terjadi autokorelasi,tidak terjadi multikolinearitas atau variable bebas saling independen, $\varepsilon_{i}$ berdistribusi normal atau dapat ditulis $\boldsymbol{\varepsilon} \stackrel{\text { iid }}{\sim} N\left(\mathbf{0}, \sigma^{2} \mathbf{I}\right)$.

Dengan menggunakan mtode OLS maka maka diperoleh :

$$
\widehat{\boldsymbol{\beta}}=\left(\mathbf{X}^{t} \mathbf{X}\right)^{-1} \mathbf{X}^{t} \mathbf{Y}
$$

matriks varian-kovarian adalah

$$
\operatorname{Var}\left(\widehat{\boldsymbol{\beta}}_{O L S}\right)=\sigma^{2}\left(\mathbf{X}^{t} \mathbf{X}\right)^{-1}
$$

sedangkan estimasi untuk $\operatorname{var}(\boldsymbol{\varepsilon})=\sigma^{2}$ OLS adalah

$$
\hat{\sigma}_{O L S}^{2}=\frac{1}{n-p}\left[\hat{\boldsymbol{\varepsilon}}^{t} \hat{\boldsymbol{\varepsilon}}\right]=\frac{1}{n-p}\left[\left(\mathbf{Y}-\mathbf{X} \widehat{\boldsymbol{\beta}}_{O L S}\right)^{t}\left(\mathbf{Y}-\mathbf{X} \widehat{\boldsymbol{\beta}}_{O L S}\right)\right]
$$

\subsection{Regresi dengan Metode Generalized Least Square}

Pelanggaran terhadap beberapa asumsi dalam model regresi linier seperti terjadinya heterokedastisitas menyebabkan metode OLS tidak tepat untuk digunakan dalam mengestimasi parameter pada model regresi linier. Heterokedastisitas adalah keadaan dimana $\operatorname{Var}(\varepsilon)$ tidak berbentuk $\sigma^{2} I$, melainkan berbentuk matriks diagonal dengan unsur-unsur pada diagonal utamanya tidak sama. Selain itu dapat juga terjadi unsur-unsur diluar diagonal untuk matriks $\operatorname{Var}(\varepsilon) \neq 0$ yang berarti pengamatan saling berkorelasi atau serial korelasi (Draper and Smith, 1992). Kasus heterokedastisitas diasumsikan bahwa $\operatorname{Var}(\varepsilon)=\sigma^{2} \Omega$ dimana $\Omega$ adalah suatu matriks berukuran $n \times n$. Untuk 


\section{A. Muthiah Nur Angriany, Georgina Maria Tinungki, Raupong}

mengatasi adanya pelanggaran asumsi pada metode OLS tersebut maka akan dilakukan penyelesaian dengan melakukan transformasi pada model regresi agar asumsi pada metode OLS terpenuhi

Pada model linear (2.5) asumsi matriks kovariansi galatnya $\sum=\sigma^{2} \Omega$, dengan matriks $\Omega$ merupakan matriks simetriks definit positif, oleh sebab itu untuk setiap matriks $\Omega$ ada matriks $\boldsymbol{P}$ nonsingular berukuran $n \times n$ sehingga $\boldsymbol{P}^{\prime} \boldsymbol{P}=\Omega$. dengan demikian $\boldsymbol{P}^{-\mathbf{1}} \Omega\left(\boldsymbol{P}^{\mathbf{- 1}}\right)^{\prime}=\boldsymbol{I}$

Kemudian pada model linier (2.5) kedua ruas akan dikalikan dengan $\boldsymbol{P}^{\mathbf{- 1}}$ sehingga akan menjadi bentuk

$\boldsymbol{P}^{-1} \boldsymbol{Y}=\boldsymbol{P}^{-1} \boldsymbol{X} \boldsymbol{\beta}+\boldsymbol{P}^{-1} \varepsilon \quad$ atau

dapat ditulis : $\boldsymbol{Y}_{\boldsymbol{b}}=\boldsymbol{X}_{\boldsymbol{b}} \boldsymbol{\beta}+\boldsymbol{f} \quad, \boldsymbol{E}(\boldsymbol{f})=\boldsymbol{P}^{-\mathbf{1}} \boldsymbol{\varepsilon}=\mathbf{0}$

dengan demikian, $\operatorname{Cov}(\boldsymbol{f})=E\left[(\boldsymbol{f}-E(\boldsymbol{f}))(\boldsymbol{f}-E(\boldsymbol{f}))^{\prime}\right]=\boldsymbol{\sigma}^{2} \boldsymbol{I}$

Setelah dilakukan transformasi ternyata model regresi memenuhi asumsi klasik, sehingga untuk mencari parameter untuk metode GLS dapat menggunakan langkah-langkah pada metode OLS yaitu:

$$
\left.\widehat{\boldsymbol{\beta}}_{G L S}=\left(\boldsymbol{X}^{\prime} \Omega^{-1} \boldsymbol{X}\right)^{-1} \boldsymbol{X}^{\prime} \Omega^{-1} \boldsymbol{Y}\right)
$$

dengan matriks varian-kovarian adalah

$$
\operatorname{Var}\left(\widehat{\boldsymbol{\beta}}_{G L S}\right)=E\left[\left(\widehat{\boldsymbol{\beta}}_{G L S}-E\left(\widehat{\boldsymbol{\beta}}_{G L S}\right)\right)\left(\widehat{\boldsymbol{\beta}}_{G L S}-E\left(\widehat{\boldsymbol{\beta}}_{G L S}\right)^{t}\right]=\sigma^{2}\left(\mathbf{X}^{t} \Omega^{-\mathbf{1}} \mathbf{X}\right)^{-1}\right.
$$

sedangkan estimasi untuk $\sigma^{2}$ GLS adalah

$$
\widehat{\boldsymbol{\sigma}}_{G L S}^{2}=\frac{1}{n-p}\left[(\mathbf{P} \widehat{\boldsymbol{\varepsilon}})^{t} \mathbf{P} \hat{\boldsymbol{\varepsilon}}\right]=\frac{1}{n-p}\left[\left(\mathbf{Y}-\mathbf{X} \widehat{\boldsymbol{\beta}}_{G L S}\right)^{t} \Omega^{-\mathbf{1}}\left(\mathbf{Y}-\mathbf{X} \widehat{\boldsymbol{\beta}}_{G L S}\right)\right]
$$

\subsection{Formula Matriks dari Faktorial RAL}

Dengan menggunakan perkalian kronecker maka persamaan (2.1) dapat ditulis dalam bentuk matriks sebagai berikut

$$
\begin{aligned}
\mathbf{Y}= & \left(\mathbf{1}_{\boldsymbol{a}} \otimes \mathbf{1}_{b} \otimes \mathbf{1}_{r}\right) \boldsymbol{\mu}+\left(\mathbf{I}_{a} \otimes \mathbf{1}_{b} \otimes \mathbf{1}_{r}\right) \boldsymbol{\alpha}+\left(\mathbf{1}_{a} \otimes \mathbf{I}_{b} \otimes \mathbf{1}_{r}\right) \boldsymbol{\beta}+\left(\mathbf{I}_{a} \otimes \mathbf{I}_{b} \otimes \mathbf{1}_{r}\right. \\
& +\left(\mathbf{I}_{a} \otimes \mathbf{I}_{b} \otimes \mathbf{I}_{r}\right) \mathcal{E}
\end{aligned}
$$

misalkan $\left[\begin{array}{llll}\boldsymbol{\mu} & \boldsymbol{\alpha}^{\mathrm{t}} & \boldsymbol{\beta}^{\mathrm{t}} & \boldsymbol{\gamma}^{\mathrm{t}}\end{array}\right]^{\mathrm{t}}=\boldsymbol{\beta}^{*}$

maka persamaan (2.13) dapat disederhanakan menjadi :

$$
\mathbf{Y}=\mathbf{X}^{*} \boldsymbol{\beta}^{*}+\boldsymbol{\varepsilon}
$$

Berdasarkan persamaan (2.5) dan (2.6) maka estimator OLS $\left(\widehat{\boldsymbol{\beta}}_{O L S}^{*}\right)$ dan GLS $\left(\widehat{\boldsymbol{\beta}}_{G L S}^{*}\right)$ dari persamaan (2.14) adalah

$$
\begin{aligned}
& \widehat{\boldsymbol{\beta}}^{*}{ }_{O L S}=\left(\mathbf{X}^{*} \mathbf{X}^{*}\right)^{-1} \mathbf{X}^{*^{\mathrm{t}}} \mathbf{Y} \\
& {\widehat{\boldsymbol{\beta}^{*}}}_{G L S}=\left(\mathbf{X}^{*^{\mathrm{t}}} \Omega^{-\mathbf{1}} \mathbf{X}^{*}\right)^{-1} \mathbf{X}^{*^{\mathrm{t}}} \Omega^{-\mathbf{1}} \mathbf{Y}
\end{aligned}
$$

Dengan matriks varian-kovarian untuk OLS dan GLS adalah

$$
\begin{aligned}
& \operatorname{Var}\left(\widehat{\boldsymbol{\beta}}^{*}{ }_{O L S}\right)=\sigma^{2}\left(\mathbf{X}^{* \mathrm{t}} \mathbf{X}^{*}\right)^{-1} \\
& \operatorname{Var}\left(\widehat{\boldsymbol{\beta}}_{G L S}\right)=\sigma^{2}\left(\mathbf{X}^{* \mathrm{t}} \Omega^{-\mathbf{1}} \mathbf{X}^{*}\right)^{-1}
\end{aligned}
$$

sedangkan estimasi untuk $\sigma^{2}$ adalah

$$
\begin{aligned}
& \widehat{\sigma}_{O L S}^{2}=\frac{1}{n-p}\left[(\widehat{\boldsymbol{\varepsilon}})^{\mathrm{t}} \widehat{\boldsymbol{\varepsilon}}\right]=\frac{1}{n-p}\left[\left(\mathbf{Y}-\mathbf{X} \widehat{\boldsymbol{\beta}}^{*}{ }_{O L S}\right)^{\mathrm{t}}\left(\mathbf{Y}-\mathbf{X} \widehat{\boldsymbol{\beta}}^{*}{ }_{O L S}\right)\right] \\
& \widehat{\sigma}_{G L S}^{2}=\frac{1}{n-p}\left[(\mathbf{P} \hat{\boldsymbol{\varepsilon}})^{\mathrm{t}} \mathbf{P} \hat{\boldsymbol{\varepsilon}}\right]=\frac{1}{n-p}\left[\left(\mathbf{Y}-\mathbf{X} \widehat{\boldsymbol{\beta}}^{*}{ }_{G L S}\right)^{\mathrm{t}} \Omega^{-\mathbf{1}}\left(\mathbf{Y}-\mathbf{X} \widehat{\boldsymbol{\beta}}^{*}{ }_{G L S}\right)\right]
\end{aligned}
$$

\section{Metode Analisis}

\subsection{Sumber Data}

Data yang digunakan pada tugas akhir ini merupakan data sekunder berupa data penelitian dari A. Yusrapardi R. (2008) mengenai pengaruh penambahan perekat tepung tapioka dan tepung gaplek serta lama penyimpanan yang berbeda terhadap sifat fisik pakan itik bentuk pellet. Sifat fisik merupakan bagian dari karakteristik mutu, parameter mutu yang dimaksud dalam penelitian A. Yusrapardi adalah besaran yang mencirikan beberapa sifat mutu produk yang diturunkan dari beberapa pengukuran sifat fisik antara lain adalah berat jenis,kerapatan tumpukan, kerapatan pemadatan tumpukan. Pada penelitian ini digunakan 


\section{A. Muthiah Nur Angriany, Georgina Maria Tinungki, Raupong}

data sekunder pengukuran fisik berat jenis dengan perlakuan penambahan bahan perekat dan lama penyimpan. Penelitian ini menggunakan rancangan faktorial acak lengkap yang terdiri dari 2 faktor dan 4 ulangan.

\subsection{Identifikasi Variable}

Tugas akhir ini menggunakan pola rancangan faktorial RAL yaitu :

1) Faktor A : Perekat yang terdiri dari 3 taraf faktor yaitu :
$\mathrm{a}_{1}$ : Tanpa perekat
$\mathrm{a}_{2}$ : Tepung Tapioka 5\%
$\mathrm{a}_{3}$ : Tepung Gaplek $5 \%$

2) Faktor $B$ : Lama peyimpanan yang terdiri dari 3 taraf faktor yaitu :

$$
\begin{aligned}
& b_{1}: 0 \text { minggu } \\
& b_{2}: 2 \text { minggu } \\
& b_{3}: 4 \text { minggu }
\end{aligned}
$$

\subsection{Metode Analisis} berikut:

Adapun langkah-langkah yang dilakukan berdasarkan tujuan penelitian adalah sebagai

1. Pengambilan data sekunder

2. Melakukan uji asumsi rancangan percobaan.

a) Uji normalitas galat menggunakan uji Liliefors

b) Uji kehomogenan variansi galat menggunakan uji Bartlett

c) Uji galat percobaan saling bebas dengan membuat plot antara nilai sisaan dengan nilai dugaan pengamatan

3. Membentuk model Faktorial RAL dalam bentuk persamaan regresi dengan menggunakan perkalian kronecker.

4. Mengestimasi komponen-komponen varian:

a) Mengestimasi parameter regresi menggunakan metode OLS (2.15)

b) Mengestimasi $\operatorname{var}(\varepsilon)=\sigma^{2}$ OLS menggunakan persamaan (2.17)

c) Membentuk persamaan regresi baru $Y_{b}=X_{b}^{*} \beta^{*}+f$

d) Mengestimasi parameter regresi menggunakan metode GLS (2.16)

e) Mengestimasi komponen variansi error menggunakan persamaan (2.18)

f) Mengestimasi komponen variansi faktor $\mathrm{A}$, faktor $\mathrm{B}$, dan faktor $\mathrm{AB}$ berdasarkan point $\mathrm{d}$

5. Menghitung KTG

6. Menghitung $\mathrm{F}_{\text {hitung }}$

7. Memberikan Kesimpulan

\section{Hasil dan Pembahasan}

\subsection{Model Rancangan Percobaan dengan Faktorial Rancangan Acak Lengkap dalam Regresi}

Model linear dari rancangan percobaan faktorial dengan rancangan acak lengkap pada persamaan (2.1) diterapkan pada data Lampiran 1, dengan faktor A dengan taraf $\mathrm{a}=3$, faktor $\mathrm{B}$ dengan taraf $b=3$, dan $r=4$ dapat dituliskan sebagai berikut :

$\mathbf{Y}=\left(\mathbf{1}_{3} \otimes \mathbf{1}_{3} \otimes \mathbf{1}_{4}\right) \boldsymbol{\mu}+\left(\mathbf{I}_{3} \otimes \mathbf{1}_{3} \otimes \mathbf{1}_{4}\right) \boldsymbol{\alpha}+\left(\mathbf{1}_{3} \otimes \mathbf{I}_{3} \otimes \mathbf{1}_{4}\right) \boldsymbol{\beta}+\left(\mathbf{I}_{3} \otimes \mathbf{I}_{3} \otimes \mathbf{1}_{4}\right) \boldsymbol{\gamma}+\left(\mathbf{I}_{3} \otimes \mathbf{I}_{3} \otimes \mathbf{I}_{4}\right) \boldsymbol{\varepsilon}$

Misalkan $\boldsymbol{\beta}^{*}=\left[\begin{array}{llll}\boldsymbol{\mu} & \boldsymbol{\alpha}^{\mathrm{t}} & \boldsymbol{\beta}^{\mathrm{t}} & \boldsymbol{\gamma}^{\mathrm{t}}\end{array}\right]^{\mathrm{t}}$ maka persamaan (4.1) dapat ditulis dalam bentuk persamaan regresi yaitu :

$$
\mathbf{Y}=\mathbf{X}^{*} \boldsymbol{\beta}^{*}+\boldsymbol{\varepsilon}
$$




\section{A. Muthiah Nur Angriany, Georgina Maria Tinungki, Raupong}

\subsection{Estimasi Komponen Variansi dengan Metode GLS dalam Rancangan Faktorial Acak Lengkap}

Metode GLS adalah pengembangan metode OLS yang digunakan apabila terjadi heterokedastisitas atau autokorelasi. Asumsi metode GLS adalah $E(\boldsymbol{\varepsilon})=\mathbf{0}, \operatorname{Var}(\boldsymbol{\varepsilon})=\boldsymbol{\sigma}^{2} \Omega ;$ dan $\boldsymbol{\varepsilon} \sim N_{p}\left(0, \sigma^{2} \Omega\right) . \Omega$ adalah suatu matriks berukuran $n \times n$ yang simetriks dan definit positif akibatnya untuk setiap matriks $\Omega$ terdapat matriks $\boldsymbol{P}$ nonsingular berukuran $n \times n$ sehingga $\boldsymbol{P}^{\prime} \boldsymbol{P}=\Omega$. dengan demikian $\boldsymbol{P}^{-\mathbf{1}} \Omega\left(\boldsymbol{P}^{-\mathbf{1}}\right)^{\prime}=\boldsymbol{I}$

Pada model linier (4.2) kedua ruas akan dikalikan dengan $\boldsymbol{P}^{\mathbf{- 1}}$ diperoleh :

$$
\boldsymbol{P}^{-1} \boldsymbol{Y}=\boldsymbol{P}^{-1} \boldsymbol{X}^{*} \boldsymbol{\beta}^{*}+\boldsymbol{P}^{-1} \boldsymbol{\varepsilon}
$$

Atau dapat ditulis : $\boldsymbol{Y}_{\boldsymbol{b}}=\boldsymbol{X}_{\boldsymbol{b}} \boldsymbol{\beta}^{*}+\boldsymbol{f} \quad ; \boldsymbol{f}=$ galat baru, $\boldsymbol{E}(\boldsymbol{f})=\boldsymbol{P}^{-\mathbf{1}} \boldsymbol{\varepsilon}=\mathbf{0}$

dengan demikian matriks kovariansi dari $\boldsymbol{f}$ dapat ditulis :

$$
\operatorname{Cov}(\boldsymbol{f})=E\left[(\boldsymbol{f}-E(\boldsymbol{f}))(\boldsymbol{f}-E(\boldsymbol{f}))^{\prime}\right]=\boldsymbol{\sigma}^{2} \boldsymbol{I}
$$

Berdasarkan persamaan (4.3) maka $\boldsymbol{f} \sim N\left(0, \sigma^{2} \boldsymbol{I}\right)$ atau telah memenuhi asumsi Homogenitas, sehingga rumus taksiran untuk GLS sebagai berikut :

$$
\widehat{\boldsymbol{\beta}}_{G L S}=\left(\mathbf{X}^{* t} \Omega^{-1} \mathbf{X}^{*}\right)^{-1} \mathbf{X}^{* t} \Omega^{-\mathbf{1}} \mathbf{Y}
$$

dengan $E\left(\widehat{\boldsymbol{\beta}}_{G L S}^{*}\right)=E\left[\left(\mathbf{X}^{* t} \Omega^{-\mathbf{1}} \mathbf{X}^{*}\right)^{-1} \mathbf{X}^{* t} \Omega^{-\mathbf{1}} \mathbf{Y}\right]=\boldsymbol{\beta}^{*}$

dan matriks varian-kovarian sebagai berikut :

$$
\operatorname{Var}\left(\widehat{\boldsymbol{\beta}}_{G L S}\right)=E\left[\left(\widehat{\boldsymbol{\beta}}_{G L S}-E\left(\widehat{\boldsymbol{\beta}}^{*}{ }_{G L S}\right)\right)\left(\widehat{\boldsymbol{\beta}}_{G L S}{ }_{G L}-E\left(\widehat{\boldsymbol{\beta}}_{G L S}{ }_{G L}\right)\right)^{t}\right]=\sigma^{2}\left(\mathbf{X}^{* t} \Omega^{-\mathbf{1}} \mathbf{X}^{*}\right)^{-1}
$$

sedangkan estimator untuk $\sigma^{2}$ GLS adalah

$$
{\widehat{\sigma^{2}}}_{G L S}=\frac{1}{n-p}\left[\left(\mathbf{Y}-\mathbf{X}{\widehat{\boldsymbol{\beta}^{*}}}_{G L S}\right)^{t} \Omega^{-\mathbf{1}}\left(\mathbf{Y}-\mathbf{X} \widehat{\boldsymbol{\beta}}_{G L S}\right)\right]
$$

dimana : $n=$ Banyaknya data observasi ; $p=$ Banyaknya variabel bebas / faktor

Taksiran $\widehat{\boldsymbol{\beta}}_{G L S}^{*}$ merupakan Best Linier Unbiased Estimator (BLUE). Sifat-sifat BLUE adalah sebagai berikut :

1. Linier, estimator yang diperoleh dengan metode GLS adalah ${\widehat{\boldsymbol{\beta}^{*}}}_{G L S}=\left(\mathbf{X}^{* t} \Omega^{-\mathbf{1}} \mathbf{X}^{*}\right)^{-1} \mathbf{X}^{* t} \Omega^{-\mathbf{1}} \mathbf{Y}$. Karena $\left(\mathbf{X}^{* t} \Omega^{-\mathbf{1}} \mathbf{X}^{*}\right)^{-1} \mathbf{X}^{* t} \Omega^{-\mathbf{1}}$ adalah matriks yang berisi angka tetap maka $\widehat{\boldsymbol{\beta}}_{G L S}$ adalah fungsi linier dari Y. sehingga $\widehat{\boldsymbol{\beta}}_{G L S}$ adalah sebuah estimator linier.

2. Tak Bias (Unbiased), estimator dikatakan tak bias jika $E(\widehat{\boldsymbol{\beta}})=\boldsymbol{\beta}$. Estimator GLS tak bias karena $E\left({\widehat{\boldsymbol{\beta}^{*}}}_{G L S}\right)=\boldsymbol{\beta}^{*}$. Hal ini ditunjukkan pada persamaan (4.4).

3. Variansi Minimum, cara menunjukkan $\widehat{\boldsymbol{\beta}}_{G L S}$ adalah estimator-estimator terbaik (best estimator), harus dibuktikan bahwa ${\widehat{\boldsymbol{\beta}^{*}}}_{G L S}$ mempunyai variansi yang terkecil atau minimum di antara variansi estimator tak bias linear yang lain.

\subsection{Penerapan Pada Data}

\subsubsection{Pengujian Asumsi pada Rancangan Percobaan}

\section{Normalitas}

Uji yang digunakan untuk mengetahui apakah data pengamatan menyebar normal adalah uji Liliefors. Berdasarkan prosedure Uji diperoleh nilai $L_{o}=0,188291$, sedangkan nilai L pada tabel kritis untuk uji Liliefors dengan taraf signifikan 0,05 diperoleh sebesar 0,147667 , karena nilai $L_{o}=$ $0,188291>L_{(0,05,36)}=0,147667$, maka dapat disimpulkan bahwa $H_{o}$ ditolak yang berarti data tidak menyebar secara normal, sehingga perlu dilakukan transformasi logaritma pada data. Hasil uji liliefors data transformasi diperoleh nilai $L_{o}=0,139051$, sedangkan nilia L pada tabel kritis untuk uji Liliefors dengan taraf signifikan 0,05 diperoleh sebesar 0,147667 , karena nilai $L_{o}<L_{(0,05,36)}$, maka dapat disimpulkan bahwa $H_{o}$ diterima yang berarti data menyebar secara normal.

\section{Kehomogenan Variansi}

Uji asumsi yang digunakan untuk memeriksa kehomogenan galat adalah uji Bartlet. Distribusi sampling Uji Bartlett dapat didekati oleh distribusi chi-square dengan derajat kebebasan (p-1). Hasil perhitungan nilai $\chi_{\text {hit }}^{2}$ pada data transformasi dengan bantuan software SAS Studio diperoleh $\chi_{\text {hit }}^{2}=$ 


\section{A. Muthiah Nur Angriany, Georgina Maria Tinungki, Raupong}

11,485336 dan nilai $\chi_{(0,05,2)}$ pada tabel nilai kritis sebaran $\chi$ diperoleh 5,991. Karena $\chi_{\text {hit }}^{2}>$ $\chi_{(0,05,2)}$, maka $\mathrm{H}_{\mathrm{o}}$ ditolak yang berarti terdapat perbedaan variansi pada perlakuan (heterokedastisitas).

\section{Kebebasan Pengamatan}

Kebebasan pengamatan dapat diamati dari plot antara nilai dugaan pengamatan dengan nilai galat ditunjukkan pada Gambar 1 berikut :

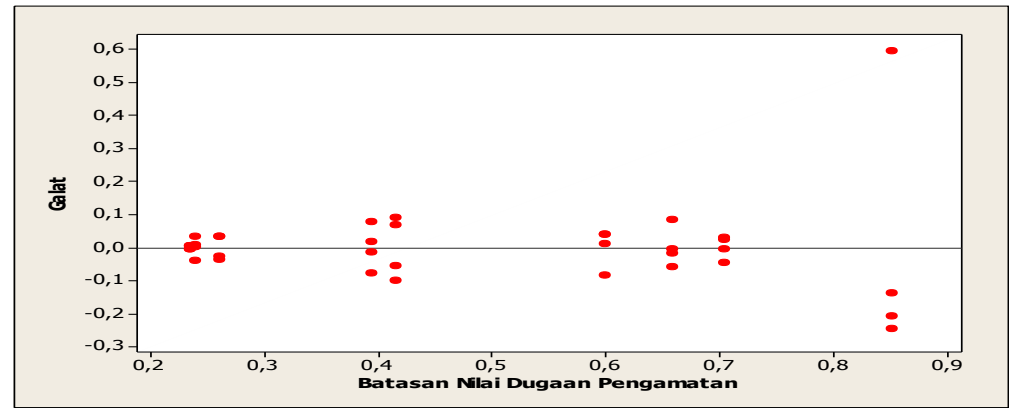

Gambar 1. Plot antara Nilai Dugaan Pengamatan dengan Nilai Galat

Pada Gambar 1 dapat dilihat bahwa titik-titik galat menyebar secara acak atau tidak membentuk pola tertentu sehingga dapat disimpulkan bahwa asumsi kebebasan galat terpenuhi.

\subsubsection{Pengujian Autokorelasi}

Autokorelasi adalah korelasi yang terjadi antara residual pada satu pengamatan dengan pengamatan lain pada model regresi. Secara umum, uji yang digunakan untuk memeriksa autokerlasi adalah Durbin-Watson. Berdasarkan Output minitab diperoleh nilai $\mathrm{DW}=2,09884$. Nilai ini terletak antara nilai $\mathrm{dl}=0,5201 \mathrm{dan} \mathrm{du}=2,7742$ (tabel Durbin-Watson) sehingga, tidak ada kesimpulan yang pasti tentang ada atau tidaknya gejalah autokerlasi dari data tersebut. Jika terjadi hal seperti ini, maka langkah yang harus dilakukan adalah dengan uji run test. Berdasarkan output SPSS diperoleh nilai Asymp. Sig. (2-tailed) $=0,612>\alpha=0,05$, maka dapat disimpulkan bahwa tidak terdapat gejalah atau masalah autokorelasi.

\subsubsection{Pengujian Hipotesis}

Hipotesi yang akan diuji adalah sebagai berikut :

(i) Faktor A tetap dengan 3 taraf dan faktor B tetap dengan 3 taraf
1) $H_{0}: \alpha_{1}=\alpha_{2}=\alpha_{3}=0$ Vs $H_{1}$ : terdapat $\alpha_{i} \neq 0, \quad i=1,2,3$
2) $H_{0}: \beta_{1}=\beta_{2}=\beta_{3}=0$ Vs $H_{1}$ : terdapat $\beta_{j} \neq 0, \quad j=1,2,3$
3) $H_{0}: \gamma_{11}=\gamma_{12}=\cdots=\gamma_{33}=0$ Vs $H_{1}$ : terdapat $\gamma_{i j} \neq 0, \quad i=1,2,3, j=1,2,3$

(ii) Faktor A tetap dengan 3 taraf $\mathrm{t}$ dan faktor $\mathrm{B}$ acak dengan 3 taraf
1) $H_{0}: \alpha_{1}=\alpha_{2}=\alpha_{3}=0$ Vs $H_{1}$ : terdapat $\alpha_{i} \neq 0, \quad i=1,2,3$
2) $H_{0}: \sigma_{\beta}^{2}=0$ Vs $H_{1}: \sigma_{\beta}^{2}>0$
1) $H_{0}: \sigma_{\gamma}^{2}=0$ Vs $H_{1}: \sigma_{\gamma}^{2}>0$

\subsubsection{Analisis Variansi pada Data}

Adapun struktur analisis variansi (ANAVA) untuk berbagai model sebagai berikut :

(i) Analisis variansi model tetap untuk data asli ditunjukkan pada tabel 4.1 berikut:

Tabel 4.1 Hasil Perhitungan ANAVA model tetap pada data asli

\begin{tabular}{|c|c|c|c|c|c|}
\hline Sumber & DB & JK & KT & $F_{\text {Hitung }}$ & $\mathrm{F}_{\text {tabel }}$ \\
\hline
\end{tabular}




\section{A. Muthiah Nur Angriany, Georgina Maria Tinungki, Raupong}

\begin{tabular}{|c|c|c|c|c|c|c|}
\hline & & & & & $5 \%$ & $1 \%$ \\
\hline $\mathrm{A}$ & 2 & 0,1793 & 0,0897 & 0,566834 & 3,354 & 5,4881 \\
\hline $\mathrm{B}$ & 2 & 4,7023 & 2,3511 & $14,86246^{* *}$ & 3,354 & 5,4881 \\
\hline $\mathrm{A} * \mathrm{~B}$ & 4 & 0,8524 & 0,2131 & 1,347155 & 2,728 & 4,1056 \\
\hline GALAT & 27 & 4,2712 & 0,1582 & & & \\
\hline TOTAL & 35 & 10,0053 & & & & \\
\hline
\end{tabular}

Sumber : Hasil olahan, 2018

Kesimpulan :

1) $F_{\text {hit }}(A)=0,566834<F_{0,05(2,27)}=3,354$, maka hipotesis nol $\left(H_{0}\right)$ diterima yang artinya tidak ada perbedaan pengaruh penambahan bahan perekat terhadap berat jenis pakan pellet.

2) $F_{\text {hit }}(B)=14,86246>F_{0,01(2,27)}=5,4881$ maka hipotesis nol $\left(H_{0}\right)$ ditolak (sangat signifikan) yang artinya ada perbedaan pengaruh lama penyimpanan pakan terhadap berat jenis pakan pellet.

3) $\left.F_{\text {hit }}(A B)=1,8926<F_{a(4,27}\right)=2,728$ maka hipotesis nol $\left(H_{0}\right)$ diterima yang artinya tidak ada pengaruh interaksi antar penambahan bahan perekat dan lama penyimpanan pakan terhadap berat jenis pakan pellet.

(ii) Analisis variansi model tetap untuk data transformasi ditunjukkan pada tabel 4.2.

Tabel 4.2 Hasil Perhitungan ANAVA model tetap pada data transformasi

\begin{tabular}{|c|c|c|c|c|c|c|}
\hline \multirow{2}{*}{ Sumber } & \multirow{2}{*}{ DB } & \multirow{2}{*}{$\mathrm{JK}$} & $\mathrm{KT}$ & \multirow{2}{*}{$\mathrm{F}_{\text {Hitung }}$} & \multicolumn{2}{|c|}{$\mathrm{F}_{\text {tabel }}$} \\
\cline { 6 - 7 } & & & & & $5 \%$ & $1 \%$ \\
\hline $\mathrm{A}$ & 2 & 0,0303 & 0,0152 & 0,74455 & 3,354 & 5,4881 \\
\hline $\mathrm{B}$ & 2 & 1,4651 & 0,7325 & $35,9953 * *$ & 3,354 & 5,4881 \\
\hline $\mathrm{A} * \mathrm{~B}$ & 4 & 0,1541 & 0,0385 & 1,8926 & 2,728 & 4,1056 \\
\hline Galat & 27 & 0,5495 & 0,0204 & & & \\
\hline Total & 35 & 2,1989 & & & & \\
\hline
\end{tabular}

Sumber : Hasil olahan, 2018

Kesimpulan :

1) $F_{\text {hit }}(A)=0,74455<F_{0,05(2,27)}=3,354$, maka hipotesis nol $\left(H_{0}\right)$ diterima yang artinya tidak ada perbedaan pengaruh penambahan bahan perekat terhadap berat jenis pakan pellet.

2) $F_{\text {hit }}(B)=35,9953>F_{0,01(2,27)}=5,4881$ maka hipotesis nol $\left(H_{0}\right)$ ditolak (sangat signifikan) yang artinya ada perbedaan pengaruh lama penyimpanan pakan terhadap berat jenis pakan pellet.

3) $\left.F_{\text {hit }}(A B)=1,8926<F_{a(4,27}\right)=2,728$ maka hipotesis nol $\left(H_{0}\right)$ diterima yang artinya tidak ada pengaruh interaksi antar penambahan bahan perekat dan lama penyimpanan pakan terhadap berat jenis pakan pellet.

(iii) Analisis variansi model tetap untuk data transformasi dengan metode GLS ditunjukkan pada tabel 4.3.

\begin{tabular}{|c|c|c|c|c|c|c|}
\hline \multirow{2}{*}{ SUMBER } & \multirow{2}{*}{ DB } & \multirow{2}{*}{$\mathrm{JK}$} & \multirow{2}{*}{$\mathrm{KT}$} & \multirow{2}{*}{$\mathrm{F}_{\text {hitung }}$} & \multicolumn{2}{|c|}{$\mathrm{F}_{\text {tabel }}$} \\
\cline { 5 - 6 } & & & & $5 \%$ & $1 \%$ \\
\hline
\end{tabular}




\section{A. Muthiah Nur Angriany, Georgina Maria Tinungki, Raupong}

\begin{tabular}{|c|c|c|c|c|c|r|r|} 
A & 2 & 0,0303 & 0,0152 & 2,10448 & 3,354 & 5,4881 & Tabel \\
4.3 \\
B & 2 & 1,4651 & 0,7325 & $101,7408 * *$ & 3,354 & 5,4881 & \\
\hline A*B & 4 & 0,1541 & 0,0385 & $5,3493 * *$ & 2,728 & 4,1056 & \\
\hline GALAT & 27 & 0,5495 & 0,0072 & & & \\
\hline TOTAL & 35 & 2,1989 & & & & \\
\hline
\end{tabular}

Sumber : Hasil olahan, 2018

Kesimpulan :

1) $F_{\text {hit }}(A)=2,10448<F_{0,05(2,27)}=3,354$, maka hipotesis nol $\left(H_{0}\right)$ diterima yang artinya tidak ada perbedaan pengaruh penambahan bahan perekat terhadap berat jenis pakan pellet.

2) $F_{\text {hit }}(B)=101,7408>F_{0,01(2,27)}=5,4881$ maka hipotesis nol $\left(H_{0}\right)$ ditolak (sangat signifikan) yang artinya ada perbedaan pengaruh lama penyimpanan pakan terhadap berat jenis pakan pellet.

3) $\left.F_{\text {hit }}(A B)=1,8926<F_{0,01(4,27}\right)=2,728$ maka hipotesis nol $\left(H_{0}\right)$ ditolak (sangat signifikasn) yang artinya ada pengaruh interaksi antar penambahan bahan perekat dan lama penyimpanan pakan terhadap berat jenis pakan pellet.

(iv) Analisis variansi model campuran (faktor A tetap dan faktor B acak) untuk data transformasi ditunjukkan pada tabel 4.4. sebagi berikut

Tabel 4.4 Hasil Perhitungan ANAVA model campuran pada data transformasi

\begin{tabular}{|l|l|l|l|l|l|l|}
\hline \multirow{2}{*}{ Sumber } & \multirow{2}{*}{$\mathrm{DB}$} & \multirow{2}{*}{$\mathrm{JK}$} & $\mathrm{KT}$ & $\mathrm{F}_{\text {Hitung }}$ & \multicolumn{2}{|l|}{$\mathrm{F}_{\text {tabel }}$} \\
\cline { 6 - 7 } & & & & & $5 \%$ & $1 \%$ \\
\hline $\mathrm{A}$ & 2 & 0,0303 & 0,0152 & 0,39341 & 6,944 & 18 \\
\hline $\mathrm{B}$ & 2 & 1,4651 & 0,7325 & 35,9953 & 3,354 & 5,4881 \\
\hline $\mathrm{A} * \mathrm{~B}$ & 4 & 0,1541 & 0,0385 & 1,8926 & 2,728 & 4,1056 \\
\hline Galat & 27 & 0,5495 & 0,0204 & & & \\
\hline Total & 35 & 2,1989 & & & & \\
\hline
\end{tabular}

Sumber : Hasil olahan, 2018

Berdasarkan data transformasi. nilai estimasi variansi model campuran berdasarkan persamaan (2.2), (2.3), dan (2.4) sebagai berikut :

$$
\begin{gathered}
\sigma_{e}^{2}=K T G=0,0204 \\
\sigma_{\beta}^{2}=\frac{1}{a r}[K T B-K T A B]=\frac{1}{12}[0,7325-0,0385]=0,057835 \\
\sigma_{\gamma}^{2}=\frac{1}{r}[K T A B-K T G]=\frac{1}{4}[0.0385-0,0204]=0,004541
\end{gathered}
$$

Kesimpulan :

1) $F_{\text {hit }}(A)=0,39342 \leq F_{0,05(2,4)}=6,944$, maka hipotesis nol $\left(H_{0}\right)$ diterima yang artinya tidak ada perbedaan pengaruh perlakuan penambahan bahan perekat terhadap berat jenis pakan pellet.

2) $\sigma_{\beta}^{2}=0,057835>0$ maka hipotesis nol $\left(H_{0}\right)$ ditolak yang artinya terdapat keragaman antar lama penyimpanan pakan terhadap berat jenis pakan pellet.

3) $\sigma_{\gamma}^{2}=0,0045411>0$ maka hipotesis nol $\left(H_{0}\right)$ ditolak yang artinya terdapat keragaman antar penambahan bahan perekat dan lama penyimpanan pakan. 


\section{A. Muthiah Nur Angriany, Georgina Maria Tinungki, Raupong}

\subsubsection{Estimasi Komponen Variansi pada Rancangan Faktorial Acak Lengkap Metode GLS}

Data pada lampiran 2 akan dibentuk menjadi persamaan regresi seperti persamaan (4.3) dengan kontruksi matriks seperti (lampiran 18).

Hasil outuput SAS Studio pada (lampiran 20) diperoleh $\hat{\sigma}_{O L S}^{2}=0,0262$ taksiran ${\widehat{\beta^{*}}}_{G L S}=$ $\left[\begin{array}{llllllll}0,27225 & 0,09785 & 0,06126 & 0,11313 & 0,07980 & 0,28128-0,08883-0,05607 & 0,20013-\end{array}\right.$ $0,046210,002110,043930,015220,133770,03722-0,05785]^{t}$. Sehingga diperoleh $\sigma_{e}^{2}=0,00716$ , $\sigma_{\beta}^{2}=0,03434$ dan $\sigma_{\alpha \beta}^{2}=0,00774$. Berdasarkan hipotesis yang dirumuskan pada point 4.3.2 maka dapat disimpulkan bahwa :

1) $F_{\text {hit }}(A)=2,12291<F_{0,05(2,27)}=3,354131$, maka hipotesis nol $\left(H_{0}\right)$ diterima yang artinya tidak ada perbedaan pengaruh penambahan bahan perekat terhadap berat jenis pakan pellet.

2) Nilai estimasi $\sigma_{\beta}^{2}$ yang diperoleh yaitu $0,03434>0$ maka hipotesis nol $\left(H_{0}\right)$ ditolak yang artinya terdapat keragaman populasi lama penyimpanan pakan terhadap berat jenis pakan pellet.

3) Nilai estimasi $\sigma_{\alpha \beta}^{2}$ yang diperoleh yaitu $0,00774>0$ maka hipotesis nol $\left(H_{0}\right)$ ditolak yang artinya terdapat keragaman populasi antar penambahan bahan perekat dan lama penyimpanan pakan.

\section{Kesimpulan} berikut:

Berdasarkan hasil dan pembahsan yang telah diperoleh maka dapat disimpulkan sebagai

a. Penduga komponen variansi dengan metode GLS pada data rancangan faktorial acak lengkap dengan faktor A 3 taraf, faktor B 3 taraf, dan 4 ulangan adalah $\widehat{\boldsymbol{\beta}}_{G L S(16 \times 1)}=$ $\left(X_{(16 x 36)}^{* t} \Omega_{(36 x 36)}^{-1} X_{(36 x 16)}^{*}\right)^{-1} X_{(16 x 36)}^{* t} \Omega_{(36 x 36)}^{-1} Y_{(36 x 1)}$

b. Estimasi komponen variansi pada rancangan faktorial acak lengkap dengan metode GLS yang diperoleh adalah $\sigma_{e}^{2}=0,00716, \sigma_{\beta}^{2}=0,03434$ dan $\sigma_{\alpha \beta}^{2}=0,00774$, yang berarti bahwa terdapat keragaman pengaruh lama penyimpanan terhadap berat jenis pakan pellet, dan terdapat keragaman interaksi antar jenis perekat dan lama penyimpanan terhadap berat jenis pakan pellet.

\section{Daftar Pustaka}

[1]. Antasari Ina., 2010. Penerapan Diagnostik Sisaan pada Model Linier Rancangan Acak Kelompok Lengkap. DI Yogyakarta : Universitas Negeri Yogyakarta

[2]. Corbeil, R. R., dan Searle, R.R., 2012. Retricted Maximum Likelihood Estimation of Variance Components in the Mixed Model. Technometrics

[3]. Gasperz, Vincent.,1994. Metode Perancangan Percobaan Untuk Ilmu-ilmu Pertanian,Ilmu-ilmu Teknik, Biologi. Bandung : CV.ARMICO.

[4]. Hartley, H.O dan Rou, J.N.K., 1967 . Maximum-likelihood Estimation for The Mixed Analysis of Variance Model. Biometrics p.93

[5]. Hasby dkk. 2013. Pendugaan Komponen Variansi Pada Model Campuran Klasifikasi Dua Arah Menggunakan Metode Restricted Maximum Likelihood (REML). Journal of Mathematics : Universitas Brawijaya, Malang.

[6]. Kariya, T. and Hiroshi, K., 2004. Generalized Least Square. John Wiley \& Sons, Ltd : Chichester.

[7]. Mattjik,A.A dan I M Sumertajay., 2002.Perancangan Percobaan dengan Aplikasi SAS dan Minitab, Jilid I. IPB Press.Bogor. 
A. Muthiah Nur Angriany, Georgina Maria Tinungki, Raupong

[8]. Montgomery,D.C.,1991.Design and Analysis of Experiments, $3^{\text {rd }}$ ed. John Wiley \& Sons,Inc. Singapore.

[9]. Patterson, H.D., \& Thompson, R., 1971. Recovery of inter-block information when blocek sizes are unequal.Bometrika,58, 545-554

[10]. Rahma, Wahyuwati., 2013. Analisis Faktorial RAL dengan Metode Generalized Least Square. Skripsi : Universitas Hasanuddin, Makassar

[11]. R. A. Yusrapardi., 2008. Pengaruh penambahan perekat tepung tapioka dan tepung gaplek serta lama penyimpanan yang berbeda terhadap sifat fisika pakan itik bentuk pellet. Skripsi : Universitas Hasanuddin, Makassar

[12]. Safitri, Nur Khamariah., 2013. Estimasi Komponen Varian pada Rancangan Faktorial Acak Lengkap dengan Metode Retriced Maximum Likelihood Skripsi : Universitas Hasanuddin, Makassar

[13]. Searle dkk., 2006. Variance Components. New York: John Wiley \& Sons.

[14]. Searle, Shayle R., 1982.Matrix Algebra Useful For Statistics. John Wiley \& Sons, Ltd : Chichester. 